\title{
The Knowledge, Attitude and Practices of Allied Healthcare Professionals and Nurses towards Blood Sugar Level Measurement (BSL) for Non-Diabetic Patients in Pre- and Post-Surgery
}

\author{
Abdulrahman Mohammed Hanash ${ }^{1}$, Supriya Kulkarni ${ }^{2}$ \\ ${ }^{1}$ Post Graduate Student, Anaesthesia Technologist, Symbiosis Institute of Health Sciences (SIHS), Pune, \\ Maharashtra, India. \\ ${ }^{2}$ M.D, Department of Anaesthesia, Maharashtra Medical Foundation, Joshi Hospital \& Ratna Memorial \\ Hospital.
}

Corresponding Author: Abdulrahman Mohammed Hanash

\begin{abstract}
Hypoglycemia complications in pre-and post-surgery are common among hospitalized patients with or without diabetes mellitus (DM) and associated with undesired treatment outcomes ${ }^{(1,2,3)}$. That derived our incentive to conduct this "cross-sectional study of total 102 randomly selected respondents" aims to assess the knowledge, attitude, and practices among allied healthcare professionals and nurses towards BSL measurement for hospitalized nondiabetic patients in pre-and post-surgery. Data for this study was obtained in a questionnaire-based format from respondents. The questionnaire includes questions on demographical data, participant's knowledge, attitude (reaction towards some hypoglycemic signs and symptoms), and evaluation of participant's practices. Analysis shows that $74.5 \%$ of participants were aware of hypoglycemia complications, and $20.5 \%$ had some knowledge, while the rest (4.9\%) were not aware. $72.5 \%$ of the participants showed the right attitude towards the signs and symptoms of hypoglycemia. The rest of the participants $(27.5 \%)$ were not able to distinguish between the signs and symptoms of cardiac complications and hypoglycemic complications. We found that $68.6 \%$ of the participants followed the guidelines of BSL measurement at their workplace (hospital) while $31.4 \%$ of participants don't. We found an association between the occupation and knowledge of the participants $(\mathrm{P}=0.046)$. A significant association between occupation and practices of the participants was also found $(\mathrm{P}=0.003)$. This study shows that nurses are more aware of hypoglycemia complications in pre-or post-surgery than AHPs. These results hint that AHPs need to expand their knowledge and awareness of hypoglycemia complications in pre-and post-surgery in order to avoid undesired treatment outcomes.
\end{abstract}

Keywords: Blood sugar level (BSL), Hypoglycemia, Non-diabetic, pre-and post-surgery, Nil-ByMouth (NBM), Allied Healthcare Professionals (AHPs).

\section{INTRODUCTION}

The instance of Hypoglycemia preand post-operation is a common issue for hospitalized patients regardless of diabetes mellitus (DM) (1,2,3). According to the American Diabetes Association (ADA), Canadian Diabetes Association (CDA), and the European Medicines Agency (EMA) hypoglycemia is defined as blood glucose levels (BSL) at or below $70 \mathrm{mg} / \mathrm{dl}(3.9$ $\mathrm{mmol} / \mathrm{L}$ ), and severe hypoglycemia as blood glucose level (BSL) at or below $40 \mathrm{mg} / \mathrm{dL}$ (2.2 $\mathrm{mmol} / \mathrm{L})$ (4). Hypoglycemia complications include dizziness, uneasiness, an increase in cardiovascular events including myocardial infarction (MI), blurred vision, loss of contrast sensitivity, and irregular hormonal response even coma 
Abdulrahman Mohammed Hanash et.al. The knowledge, attitude and practices of allied healthcare professionals and nurses towards blood sugar level measurement (BSL) for non-diabetic patients in pre- and post-surgery.

(5). Patients undergoing a surgical procedure that requires general anaesthesia are asked to fast for 8 to 12 hours- or even longerbefore surgery which is called Nil-ByMouth (NBM) ${ }^{(6)}$. Fasting is recommended for all major surgical procedures requiring general anesthesia in order to avoid serious complications intraoperatively (6). Nil By Mouth (NBM) status can cause hypoglycemia and its related preoperative complications in non-diabetic patients (7). Morbidity, mortality, and duration of hospitalization increases for those patients associated with hypoglycemia perioperative periods $(3,8,9)$. Postoperative infection rate increases if associated with preoperative hypoglycemia (10). Large population studies have highlighted the potential of NBM patients to experience hypoglycaemic states in hospitals and are thereby an at-risk hospital population. For example, a retrospective cohort study conducted on hospitalized patients with or without diabetes mellitus showed that the incidence of hypoglycemia is between $3.5 \%$ to $10.5 \%$ among 31,970 hospitalized patients ${ }^{(11) .}$ In a similar study--another large observational study that gathered data from 126 hospitals showed that the incidence of hypoglycemia and severe hypoglycemia among patients who were admitted to the ICU were between $1.9 \%$ and $10 \%$. ${ }^{(12) .}$ In this study, we aim to assess the knowledge of allied healthcare professionals and nurses towards some serious complications of hypoglycemia. We also wanted to understand their attitudes and practices towards blood sugar level (BSL) measurement for nondiabetic patients before and after surgery. Having this information would help inform training sessions and hospital policies to avoid such undesired complications arising in pre-and postsurgery due to hypoglycemia. These changes we believe would help improve treatment outcomes.

\section{Objective}

In this study, we aim to assess the knowledge, attitude, and practices among

allied healthcare professionals and nurses towards blood sugar level (BSL) measurement for hospitalized nondiabetic patients in pre-and post-surgery.

\section{MATERIAL AND METHODS}

A cross-sectional study was used for this study. A convenience sampling study design was undertaken with a population of 102 participants. Participants are from different health care specializations. A wellstructured questionnaire containing subsections like demographic data, knowledge, attitude, and practices regarding BLS measurement in pre-and post-operation was constructed and circulated to hospitals. This questionnaire-known as the "knowledge attitude and practices questionnaire"- method was used to collect the required data. Demographical data included age, gender, and occupation. 14 questions covered aspects of knowledge, attitude, and practices of allied healthcare professionals and nurses towards pre-and post-surgery blood sugar level (BSL) measurement in non-diabetic patients. The questionnaire had a multiple-choice styled question as well as more specific questions pertaining to the knowledge of AHPs towards hypoglycaemic conditions- for example, whether the participants were aware of hypoglycaemic complications like seizures and arrhythmias, loss of consciousness, increasing the rate of morbidity and mortality, and increasing the rate of infection postoperatively. In order to assess the attitude of participants, the questionnaire covered participants' reactions and specific actions they took towards the most common signs and symptoms of hypoglycemia like sweating, tremors, dizziness, and tachycardia. In order to measure the practices of participants, the questionnaire sought answers to specific guidelines available at hospitals for BSL measurement and whether these guidelines included non-diabetic patients. 
Abdulrahman Mohammed Hanash et.al. The knowledge, attitude and practices of allied healthcare professionals and nurses towards blood sugar level measurement (BSL) for non-diabetic patients in pre-and post-surgery.

\section{Inclusion criteria}

All allied healthcare professionals from various specializations- Cardiac Care, Respiratory Therapy, OT and Anesthesia, etc.- like technicians, technologists, therapists, and nurses were included. These professionals are in direct contact with patients who are suitable candidates for our study. Since our data collection method was through an online questionnaire, online access for participants was a must- no telephonic interview or face-to-face contact with participants was established. AHPs and nurses in selected hospitals of Pune city were administered the questionnaire based on the geographical region under question.

\section{Exclusion criteria}

Healthcare professionals and nurses who are not in direct contact with the patients such as OT managers and or not working in the area of our study and also participants who don't have access to the online questionnaire due to reasons of poor internet connectivity.

\section{Data entry and analysis}

After receiving the data, we have reviewed the data for inconsistencies if any, and re-examined them again before encoding in order to avert any kind of errors. Data coding was carried out before entering using Excel Data Entry. Statistical Package for Social Science (IBM SPSS) was used for entering the data as well as data analysis.

\section{ANALYSIS}

Analysis was performed to obtain the percentages of the participant's demographics (Table-1).

Table 1: characteristics of the participants $(n=102)$.

\begin{tabular}{|c|c|c|c|}
\hline $\begin{array}{l}\text { Sr. } \\
\text { No. }\end{array}$ & Extraneous Variables & $\begin{array}{l}\text { Frequency } \\
\text { (f) }\end{array}$ & $\begin{array}{l}\text { Percentage } \\
(\%)\end{array}$ \\
\hline \multirow[t]{4}{*}{1} & \multicolumn{3}{|l|}{ Age } \\
\hline & 20-30 years old & 82 & $80 \%$ \\
\hline & $30-40$ years old & 9 & $8.8 \%$ \\
\hline & Above 40 years old & 11 & $10.8 \%$ \\
\hline \multirow[t]{3}{*}{2} & \multicolumn{3}{|l|}{ Gender } \\
\hline & Male & 23 & $22.5 \%$ \\
\hline & Female & 79 & $77.5 \%$ \\
\hline \multirow[t]{3}{*}{3} & \multicolumn{3}{|l|}{ Occupation } \\
\hline & healthcare & 52 & $51 \%$ \\
\hline & Nurses & 50 & $49 \%$ \\
\hline
\end{tabular}

In terms of age, (Table 1; row 1) shows that our participants were predominantly ( $80 \%$ of the participants) in the age range of $20-30$ years. Where $(8.8 \%)$ of participants age is between $30-40$ years. And the rest of the participants (10.8\%) are above 40 years old. Table- 1 also shows that $77.5 \%$ of participants are females (Table 1; row 2). In row 3 of Table 1, for our further study, we divided the participants into two groups (1st group of nurses and the 2nd group includes the rest of allied healthcare specialists such as technicians and technologists).

\begin{tabular}{|c|c|c|c|}
\hline $\begin{array}{l}\text { Sr. } \\
\text { No. }\end{array}$ & Extraneous Variables & $\begin{array}{l}\text { Frequency } \\
\text { (f) }\end{array}$ & $\begin{array}{l}\text { Percentage } \\
(\%)\end{array}$ \\
\hline \multirow[t]{4}{*}{4} & \multicolumn{3}{|c|}{ Knowledge regarding complications of hypoglycaemia pre- and post-surgery } \\
\hline & Yes & 76 & $74.5 \%$ \\
\hline & No & 5 & $4.9 \%$ \\
\hline & Some of them & 21 & $20.6 \%$ \\
\hline \multirow[t]{4}{*}{5} & \multicolumn{3}{|c|}{$\begin{array}{l}\text { Knowledge regarding specific complications in pre- and post-surgery: Seizures, Loss of consciousness, increasing in } \\
\text { morbidity and mortality rate, increasing in post-operative infection rate. }\end{array}$} \\
\hline & Yes & 76 & $74.5 \%$ \\
\hline & No & 15 & $14.7 \%$ \\
\hline & Some of them & 11 & $10.8 \%$ \\
\hline \multirow[t]{3}{*}{6} & \multicolumn{3}{|c|}{ Knowledge regarding "hypoglycaemia can lead to death" } \\
\hline & Yes & 93 & $91.2 \%$ \\
\hline & No & 9 & $8.8 \%$ \\
\hline \multirow[t]{4}{*}{7} & \multicolumn{3}{|c|}{ Knowledge regarding Nil by mouth (NBM) can cause hypoglycaemia } \\
\hline & Yes & 52 & $51 \%$ \\
\hline & No & 12 & $11.8 \%$ \\
\hline & May be & 38 & $37.3 \%$ \\
\hline
\end{tabular}


Abdulrahman Mohammed Hanash et.al. The knowledge, attitude and practices of allied healthcare professionals and nurses towards blood sugar level measurement (BSL) for non-diabetic patients in pre- and post-surgery.

Table 2 shows the result of the knowledge of participants. Participants were asked whether they are aware of hypoglycemia complications in pre-and post-surgery and we found that $74.5 \%$ of the participants were aware, in which 20.6 $\%$ of the participants had some knowledge regarding the hypoglycaemic complications in pre-and post-surgery, and the rest of the participants $(4.9 \%)$ were not aware of such complications. Participants also were asked whether they are aware of some specific hypoglycaemic complications in pre-and post-surgery to be more accurate in knowledge assessment. The Specific complications were asked are: A) Seizures, B) loss of consciousness, C) Increasing in morbidity and mortality rate, D) Increasing in postoperative infection rate, and we found that $74.5 \%$ of participants were aware of the specifically mentioned complications as shown in (figure-4.1). While $10.8 \%$ of the participants were aware of some of the above-mentioned complications and the rest of the participants $(14.7 \%)$ were unaware. "Severe hypoglycemia can lead to death", which's one of the severe and most dangerous complications of hypoglycemia. Participants were asked if they are aware of that specific complication and results show that $91.2 \%$ of the participants were aware of that complication of which $8.8 \%$ of the participants were not aware. Participants were asked whether they are aware that Nil by Mouth (NBM) preoperatively can cause hypoglycemia and we found that $51 \%$ of the participants were aware, of which 37.3 $\%$ were not sure whether Nil by Mouth (NBM) can cause hypoglycemia or not, and the rest $(11.8 \%)$ were not aware.

\begin{tabular}{|c|c|c|c|}
\hline Sr. No. & Extraneous Variables & $\begin{array}{l}\text { Frequency } \\
\text { (f) }\end{array}$ & $\begin{array}{l}\text { Percentage } \\
(\%)\end{array}$ \\
\hline \multirow[t]{4}{*}{1} & \multicolumn{3}{|c|}{ Attitude towards specific hypoglycaemic complications (sweating, shakiness, dizziness, and tachycardia) } \\
\hline & $\begin{array}{l}\text { Measure (BSL) } \\
\text { (Right attitude) }\end{array}$ & 74 & $72.5 \%$ \\
\hline & $\begin{array}{l}\text { Give antiarrhythmic drug } \\
\text { (Wrong attitude) }\end{array}$ & 24 & $23.5 \%$ \\
\hline & $\begin{array}{l}\text { Nothing } \\
\text { (Wrong attitude) }\end{array}$ & 4 & $3.9 \%$ \\
\hline \multirow[t]{4}{*}{2} & \multicolumn{3}{|c|}{ Participant's willingness to follow the guidelines of BSL measurement } \\
\hline & Yes & 73 & $71.6 \%$ \\
\hline & No & 7 & $9.6 \%$ \\
\hline & May be & 22 & $21.6 \%$ \\
\hline \multirow[t]{3}{*}{3} & \multicolumn{3}{|c|}{ Believes regarding improvement outcomes if BSL is measured regularly in pre- and post-surgery. } \\
\hline & Yes & 94 & $92.2 \%$ \\
\hline & No & 8 & $7.8 \%$ \\
\hline
\end{tabular}

Table 3 describes the result of the participant's attitude towards some hypoglycaemic complications (sweating, shakiness, dizziness, and tachycardia). The mentioned signs and symptoms are mostly the major signs and symptoms of hypoglycemia to be more accurate in attitude assessment. Our analysis shows that $72.5 \%$ of participants showed the right attitude which is "measuring blood sugar level (BSL)". In which $23.5 \%$ of the participants could not distinguish between the signs and symptoms of cardiac complications and hypoglycemia complications. And the rest of the participants $(3.9 \%)$ tend not to take any action. We then asked the participants whether they are willing to measure BSL for non-diabetic patients in pre-and postsurgery or not and the result was as follows: A) $71.6 \%$ of the participants showed their willingness to follow the guidelines of BSL measurement of non-diabetic patients in pre-and post-surgery. B) $21.6 \%$ of the participants responded as they might follow the guidelines of BSL measurement of nondiabetic patients in pre-and post-surgery. C) Rest of the participants $6.9 \%$ were unwilling to follow the guidelines of BSL measurement of non-diabetic patients in pre-and post-surgery. We found that $92.2 \%$ of the participants in our study believe that measuring blood sugar level for hospitalized patients including non-diabetic patients in 
Abdulrahman Mohammed Hanash et.al. The knowledge, attitude and practices of allied healthcare professionals and nurses towards blood sugar level measurement (BSL) for non-diabetic patients in pre- and post-surgery.

pre-and post-surgery will improve the treatment outcomes.

Figure 4: Practices of participants regarding hypoglycaemia complications in pre-and post-surgery $(n=102)$.

\begin{tabular}{|l|l|l|l|}
\hline $\begin{array}{l}\text { Sr. } \\
\text { No }\end{array}$ & $\begin{array}{l}\text { Extraneous } \\
\text { Variables }\end{array}$ & $\begin{array}{l}\text { Frequency } \\
\text { (f) }\end{array}$ & $\begin{array}{l}\text { Percentage } \\
(\%)\end{array}$ \\
\hline \multirow{4}{*}{} & $\begin{array}{l}\text { Availability of a guideline for BSL measurement in } \\
\text { pre- and post-surgery }\end{array}$ \\
\cline { 2 - 4 } & Yes & 73 & $71.6 \%$ \\
\cline { 2 - 3 } & No & 29 & $28.4 \%$ \\
\hline \multirow{4}{*}{$\begin{array}{l}\text { Whether that guideline includes nondiabetic patients } \\
\text { or not }\end{array}$} & 62 & $60.8 \%$ \\
\cline { 2 - 3 } & Yes & 62 & $39.2 \%$ \\
\cline { 2 - 3 } & No & 40 & $68.6 \%$ \\
\hline 3 & $\begin{array}{l}\text { Insisting of BSL measurement in pre- and post- } \\
\text { surgery. }\end{array}$ \\
\cline { 2 - 3 } & Yes & 70 & $31.4 \%$ \\
\cline { 2 - 3 } & No & 32 & \\
\hline
\end{tabular}

Figure 4.4- shows the result of the participant's practices. The analysis shows that $71.6 \%$ of the participants have a guideline at their workplace regarding BSL measurement in pre-and post-surgery while $28.4 \%$ don't have a guideline for measuring BSL of the patients in pre and pot surgery. Participants who respond as they have a guideline for BSL measurement in pre-and post-surgery were asked whether

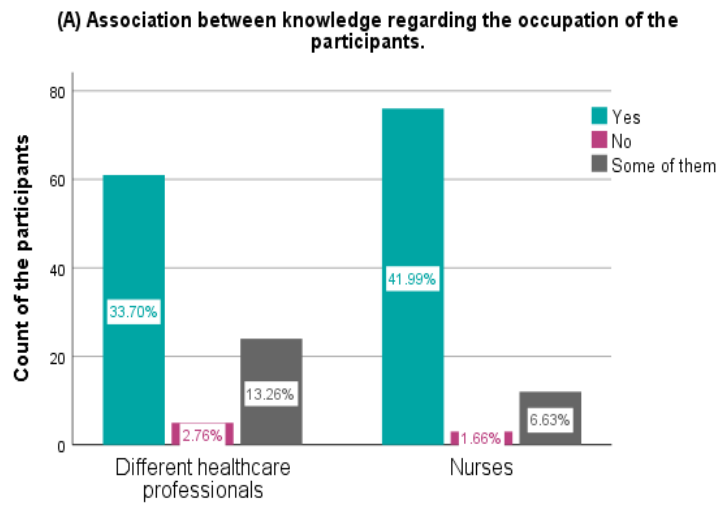

Occupation of the participants this guideline includes non-diabetic patients or not and we found that $60.8 \%$ of them approved that the guideline which is available at their workplace includes nondiabetic patients in which $39.2 \%$ respond as the guideline which is available at their workplace doesn't include non-diabetic patients. Participants then were asked whether there's a supervision of following the BSL measurement in pre-and postsurgery, and we found that $68.6 \%$ of participants have supervision at their workplace for BSL measurement in nondiabetic patients in pre-and post-surgery and they follow it. Where $31.4 \%$ of the participants responded as they don't have supervision at their workplace that insists on BSL measurement of non-diabetic patients in pre-and post-surgery.

Table 5: - association between knowledge, attitude, and practices regarding the occupation of participants.

\begin{tabular}{|l|l|l|}
\hline Sr. No. & Characteristics & p Value \\
\hline 1 & Knowledge & 0.046 \\
\hline 2 & Attitude & 0.387 \\
\hline 3 & Practices & 0.003 \\
\hline
\end{tabular}

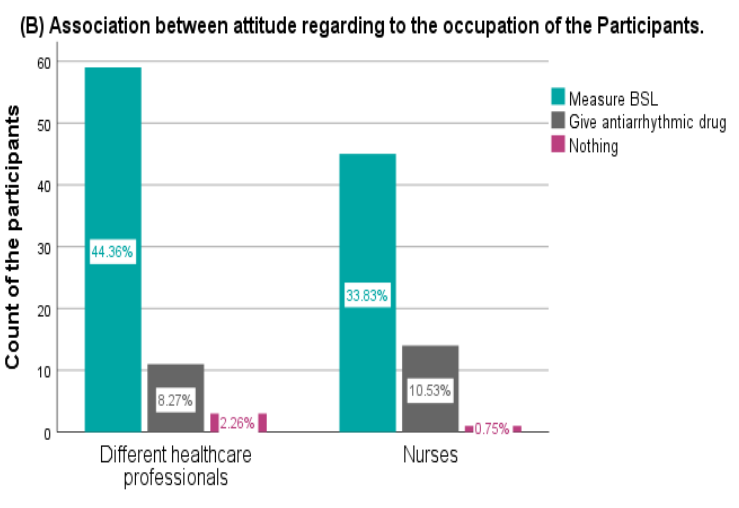

Occupation of the participants

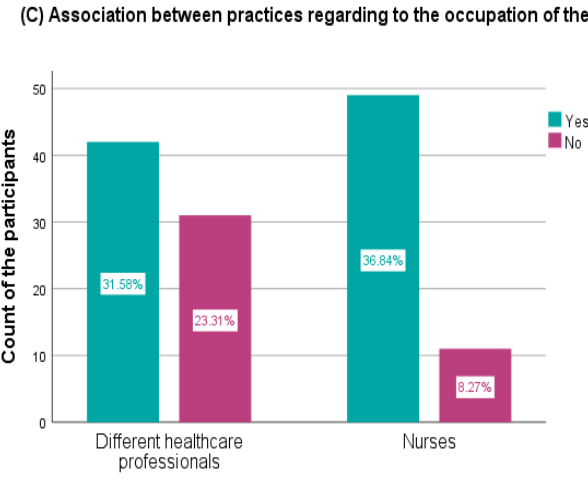

Occupation of the participants

Figure 1- (A, B, C): - association between knowledge, attitude, and practices with regards to the occupation of the participants. 
Abdulrahman Mohammed Hanash et.al. The knowledge, attitude and practices of allied healthcare professionals and nurses towards blood sugar level measurement (BSL) for non-diabetic patients in pre- and post-surgery.

An effort was made to find out the association between knowledge, attitude, and practices of the participants regarding their occupation. Chi-square test was used in order to find out this association. From the outcomes of the Chi-square test, we found that there is a significant association between knowledge and occupation of the participants $\mathrm{P}=0.046$ as shown in (Table-5, Figure-A). Analysis of this study also shows that the occupation of the participants is significantly associated with their practices $\mathrm{P}=0.003$ as shown in (Table-5, Figure-C). We did not find a significant association between attitude and occupation of the participants. Further, we tried to find the association between knowledge, attitude, and practices regarding the participant's gender. Chi-square test was used to obtain that association. The results of Chi-square analysis showed an association but have no statistical significance.

\section{DISCUSSION}

The findings of our study highlight the importance of awareness regarding hypoglycemia complications in pre-and post-surgery regardless of diabetes mellitus (DM). The allied healthcare professionals and nurses surveyed in our study had good knowledge regarding hypoglycemia complications in pre-and post-surgery $74.5 \%$ and $20.6 \%$ had some knowledge, with only $4.9 \%$ were not aware of hypoglycemia complications, but we found an association between the knowledge of the participants and their occupation $\mathrm{P}=0.046$. These findings are also similar to another descriptive study in terms of knowledge not an association between the occupation of nurses and their knowledge which was conducted among 31 nurses where the mean knowledge regarding hypoglycemia among the participants was $81.8 \%$ (13). Another descriptive cross-sectional study that supports our findings was carried throughout the period 2nd of December 2013 -to- 31st of January 2015 on the Assessment of Nurses' Knowledge and Attitude about Hypoglycaemia at Mosul
City Hospital among 247 nurses found that the nurses' knowledge was highly significant ${ }^{(14) .}$ However, our study disagrees with a study was conducted in the Philippines among 326 healthcare providers in the Philippine General Hospital towards In-Patient Hypoglycaemia and its Management which found low scores of the overall knowledge among healthcare providers and nurses who participated in their study ${ }^{(15) .}$ In our study, we found that good knowledge about hypoglycemia complications in pre-and post-surgery has led to a good attitude towards hypoglycemia complications. The percentage of the right attitude among allied healthcare professionals and nurses in our study is $72.5 \%$, and the percentage of knowledge is $74.5 \%$, these findings are quite similar to the previous mentioned descriptive crosssectional study which was carried in 2015 on the Assessment of Nurses' Knowledge and Attitude about Hypoglycaemia at Mosul City Hospital among 247 nurses, which found that good knowledge led to good attitude (14). However, our study findings regarding the attitude of allied healthcare professionals and nurses are the opposite of the findings of a study which was conducted in the Philippines among 326 healthcare providers in the Philippine General Hospital towards In-Patient Hypoglycaemia and its Management which found no association between attitude and knowledge of the participants ${ }^{(15)}$ In this study, $71.6 \%$ of the participants follow the guidelines of BSL measurement at their workplace and the same percentages are willing to follow any specific guidelines regarding BSL measurement for non-diabetic patients. However, $39.2 \%$ of our participants don't have a guideline at their workplace that includes BSL measurement for non-diabetic patients and to compare our results to another study on a "National Survey of Physicians' and Allied Health Professionals' Practices and Perspectives Regarding Hypoglycaemia Management which was conducted among 671 physicians and allied health professionals (AHPs), found that only 
Abdulrahman Mohammed Hanash et.al. The knowledge, attitude and practices of allied healthcare professionals and nurses towards blood sugar level measurement (BSL) for non-diabetic patients in pre-and post-surgery.

$21 \%$ of physicians and $40 \%$ of non-CDE AHPs confirmed that their practice is always driven by the current guidelines. The study also shows that $56 \%$ of the physicians and $43 \%$ of AHPs who participated in their study indicated that they are worried about hypoglycemia and that caused them to modify recommended guidelines to manage patient's hypoglycemia ${ }^{(16) .}$

\section{CONCLUSION}

We found that $74.5 \%$ of participants were aware of the hypoglycaemic complications in pre-and post-surgery. We also found that $72.5 \%$ of participants had shown the right attitude towards hypoglycaemic complications signs and symptoms. This study shows that $68.6 \%$ of the participants follow the guidelines of blood sugar level (BSL) measurement at their workplace (hospitals). A significant association between participant's practices and their occupation $\mathrm{P}=0.003$ was found in this study. Our study hints that there is an association between the age of the participants and their attitude. Therefore, we advise healthcare professionals to expand their knowledge and awareness towards hypoglycemia complications in pre-and post-surgery to avoid undesired treatment outcomes.

\section{Acknowledgement: None}

\section{Conflict of Interest: None}

\section{Source of Funding: None}

\section{Ethical Approval: Approved}

\section{REFERENCES}

1. Akirov A, Grossman A, Shochat T, Shimon I. Mortality among hospitalized patients with hypoglycemia: insulin related and noninsulin related. J Clin Endocrinol Metab. 2017;102(2):416-24. doi: 10.1210/jc.2016-2653, PMID 27854553.

2. Sako A, Yasunaga H, Matsui H, Fushimi K, Hamasaki H, Katsuyama H, Tsujimoto T, Goto A, Patel S. Hospitalization with hypoglycemia in patients without diabetes mellitus: A retrospective study using a national inpatient database in Japan, 20082012. Medicine (United

States). 2017;96(25).

doi: 10.1097/MD.0000000000007271.

3. Garg R, Hurwitz S, Turchin A, Trivedi A. Hypoglycemia, with or without insulin therapy, is associated with increased mortality among hospitalized patients. Diabetes Care. 2013;36(5):110710. doi: 10.2337/dc12-1296, PMID 23248192.

4. Balijepalli C, Druyts E, Siliman G, Joffres M, Thorlund K, Mills EJ. Hypoglycemia: a review of definitions used in clinical trials evaluating antihyperglycemic drugs for diabetes. Clin Epidemiol. 2017;9:291-6. doi: 10.2147/CLEP.S129268, PMID 28579834.

5. Kalra S, Mukherjee JJ, Venkataraman S, Bantwal G, Shaikh S, Saboo B, Das AK, Ramachandran A. Hypoglycemia: the neglected complication. Indian J Endocrinol Metab. 2013;17(5):819-34. doi: 10.4103/2230-8210.117219, PMID 24083163.

6. Dalal KS, Rajwade D, Suchak R. 'Nil per oral after midnight': is it necessary for clear fluids? Indian J Anaesth. 2010;54(5):445-7. doi: 10.4103/0019-5049.71044, PMID 21189883.

7. Gul A, Andsoy II, Ozkaya B. Preoperative fasting and patients' discomfort. Indian J Surg. 2018;80(6):549-53. doi: 10.1007/s12262-017-1657-4.

8. Hulkower RD, Pollack RM, Zonszein J. Understanding hypoglycemia in hospitalized patients. Diabetes Manag (Lond). 2014;4(2):165-76. doi: 10.2217/DMT.13.73, PMID 25197322.

9. Vriesendorp TM, DeVries JH, van Santen S, Moeniralam HS, de Jonge E, Roos YB, Schultz MJ, Rosendaal FR, Hoekstra JB. Evaluation of short-term consequences of hypoglycemia in an intensive care unit. Crit Care Med. 2006;34(11):2714-

8. doi:

10.1097/01.CCM.0000241155.36689.91, PMID 16943734.

10. Law TY, Moeller E, Hubbard ZS, Rosas S, Andreoni A, Chim HW. Preoperative hypoglycemia and hyperglycemia are related to postoperative infection rates in implant-based breast reconstruction. 
Abdulrahman Mohammed Hanash et.al. The knowledge, attitude and practices of allied healthcare professionals and nurses towards blood sugar level measurement (BSL) for non-diabetic patients in pre-and post-surgery.

J Surg Res. 2018;232:437-41. doi: 10.1016/j.jss.2018.06.068, PMID 30463754.

11. Boucai L, Southern WN, Zonszein J. Hypoglycemia-associated mortality is not drug-associated but linked to comorbidities. Am J Med. 2011;124(11):10 28-35. doi: 10.1016/j.amjmed.2011.07.011, PMID 22017781.

12. Cook CB, Kongable GL, Potter DJ, Abad VJ, Leija DE, Anderson M. Inpatient glucose control: a glycemic survey of 126 U.S. hospitals. J Hosp Med. 2009;4(9):E7E14. doi: 10.1002/jhm.533, PMID 20013863.

13. Waheed N. Nurses' knowledge of blood glucose levels and the management of hypoglycaemic and hyperglycaemia: A descriptive study. Madridge J Nurs. 2017; 2(1):56-62. doi: 10.18689/mjn-1000110.

14. Altahan YM. Assessment of nurses' knowledge and attitude about hypoglycemia at Mosul City Hospital. College of Nursing, University of Mosul; 2016.
15. Isnani SJ, Macalalad-Josue A, Jimeno CA. Knowledge, attitudes and practices of health care providers in the Philippine General Hospital towards inpatient hypoglycemia and its management. Acta Med Philipp. 2021;55(1) . doi: 10.47895/amp.v55i1.2926.

16. Reichert $S$, Harris $S$, Mequanint $S$, Ryan BL, Webster-Bogaert S, RatzkiLeewing A, Brown JB. A national survey of physicians' and allied health professionals' practices and perspectives regarding hypoglycemia manag ement: the InHYPO-DM study Image 8. Can J Diabetes. 2016;40(5):S58-9. doi: 10.1016/j.jcjd.2016.08.164.

How to cite this article: Abdulrahman Mohammed Hanash, Kulkarni S. The knowledge, attitude and practices of allied healthcare professionals and nurses towards blood sugar level measurement (BSL) for nondiabetic patients in pre- and post-surgery. Int $J$ Health Sci Res. 2021; 11(7): 227-234. DOI: https://doi.org/10.52403/ijhsr.20210731 